\title{
A cultura lúdica enquanto estratégia de sobrevivência e resistência no bairro de Bodocongó
}

\author{
Nayara Suênia de Oliveira \\ Eduardo Ribeiro Dantas
}

LEMOS, EMBC., DANTAS, ER., and CHAO, CHN., orgs. De portas abertas para o lazer: a cultura lúdica nas comunidades de Bairro [online]. Campina Grande: EDUEPB, 2009. 184 p. ISBN 978-85-

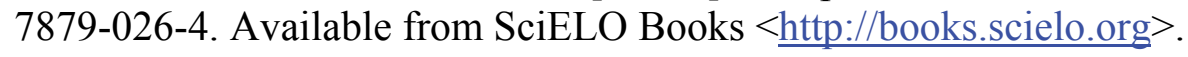

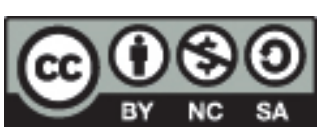

All the contents of this work, except where otherwise noted, is licensed under a Creative Commons Attribution-Non Commercial-ShareAlike 3.0 Unported.

Todo o conteúdo deste trabalho, exceto quando houver ressalva, é publicado sob a licença Creative Commons Atribuição Uso Não Comercial - Partilha nos Mesmos Termos 3.0 Não adaptada.

Todo el contenido de esta obra, excepto donde se indique lo contrario, está bajo licencia de la licencia Creative Commons Reconocimento-NoComercial-CompartirIgual 3.0 Unported. 


\title{
A cultura lúdica enquanto estratégia de sobrevivência e resistência no bairro de Bodocongó
}

\author{
Nayara Suênia de Oliveira \\ Eduardo Ribeiro Dantas
}

A intersetorialidade é um princípio de gestão pública que vem sendo bastante discutido e incentivado hoje em dia, principalmente quando a intervenção do Estado se dá em campos multidisciplinares como o do lazer. Prova disso, são os resultados da pesquisa que ora apresentamos, frutos de uma Chamada Pública do Ministério do Esporte, cujo objetivo maior foi estimular a produção do conhecimento no campo da gestão esportiva, tendo como um de seus eixos principais, a integração de políticas públicas de esporte recreativo e de lazer a outras políticas de desenvolvimento social, numa perspectiva de gestão intersetorial.

Do ponto de vista jurídico-administrativo, a gestão intersetorial do lazer vem sendo abordada por autores como Chemin (2007), para quem a efetivação do direito ao lazer à população brasileira, não depende apenas de uma política específica promovida pelo Estado, mas da elaboração e consolidação de diversas políticas públicas em áreas correlatas, tais como o desenvolvimento urbano.

Cada vez mais debatida no âmbito acadêmico e social, a importância do espaço urbano para o lazer vem sendo discutida já, há algum tempo, na Educação Física brasileira. Marcellino (2002), por exemplo, ao tratar de questões que envolvem a democratização cultural no país, afirma que para democratizarmos o lazer, precisamos antes de qual- 
quer coisa, democratizar o espaço urbano, já que no cotidiano da população, o espaço para o lazer é necessariamente o espaço da cidade.

Espaço este, que vem sendo vitimado pelo crescimento urbano desordenado e pela especulação imobiliária, o que na visão do autor, reduz não só os locais para a vivência dos interesses físicos do lazer, como também, compromete a estética e as possibilidades de contemplação da cidade (MARCELLINO, 2002).

Diante desse quadro, o planejamento das cidades brasileiras emerge tanto como uma necessidade da população, no tocante às possibilidades de experiências lúdicas, quanto um desafio a ser enfrentado pelo poder público, quando pensamos especificamente em políticas públicas de esporte recreativo e de lazer.

Necessidade, pelo fato da experiência do lazer está intimamente relacionada à experiência da cidade e, consequentemente, ao seu planejamento. Desafio, porque as cidades brasileiras têm como característica histórica, justamente a falta de planejamento, razão de muitos de seus problemas atuais (CHEMIN, 2007).

Um outro aspecto que gostaríamos de destacar no momento, em relação ao planejamento de nossas cidades, é a possibilidade de nos depararmos com certos modelos de urbanismo, que não possibilitam a apropriação corporal dos espaços urbanos, por parte da população em geral. Ou, quando assim não o fazem, favorecem a redução das possibilidades de experiência corporal dos cidadãos, às vivências do esporte institucionalizado, o que, no nosso entendimento, torna-se tão problemático quanto a primeira hipótese.

Em síntese, o que acontece nesses casos, é que, quando a cidade se oferece à nossa apropriação corporal, não sendo apenas mais um cenário para o olhar do turista, o faz na perspectiva da lógica esportiva, onde o que importa é o rendimento e a utilidade da gestualidade humana.

Partilhando da ideia discutida por Soares (2001), para quem a arquitetura é um caso particular de linguagem e uma possibilidade concreta de materialização de discursos, questionamos não só a falta de planejamento urbano por parte do poder público, em relação à vivên- 
cia da cultura lúdica da população, mas também, um tipo de planejamento que não leva em conta os desejos e as práticas diárias dos moradores das cidades brasileiras, negando a experiência corporal urbana em nome da estética do espetáculo ${ }^{1}$, ou privilegiando os códigos padronizados do esporte performance, em detrimento das mais diversas manifestações culturais, vividas em ruas e esquinas de todo o país.

Compreendemos que as políticas públicas intersetoriais de lazer e desenvolvimento urbano, devem rever alguns conceitos quanto ao planejamento das cidades, principalmente no tocante às possibilidades de experiências corporais da população. Um primeiro ponto, a ser levado em conta, é o processo de espetacularização das cidades contemporâneas, que está diretamente relacionado ao empobrecimento da experiência urbana corporal.

A redução da ação urbana, ou seja, o empobrecimento da experiência urbana pelo espetáculo leva a uma perda da corporeidade, os espaços urbanos se tornam simples cenários, sem corpo, espaços desencarnados (BRITO; JACQUES, 2008, p. 80).

0 urbanismo atual, pensado a partir de uma política pública intersetorial de lazer, não pode perder de vista a condição corporal do cidadão. A separação do espaço urbano do seu caráter experiencial e corporal pode torná-lo uma experiência desastrosa (BRITO; JACQUES, 2008).

Acontece que aqueles que pensam a cidade, que projetam e implementam políticas públicas urbanas, vêm desconsiderando sua dimensão de espaço público, destinada ao encontro e ao convívio social, efetivados nas relações corporais dos cidadãos. Desse modo, as diversas formas de habitar o espaço e viver o tempo das cidades, que as caracterizam e as constituem simultaneamente, tornam-se invisíveis, ou melhor, são invisibilizadas pelos processos hegemônicos de regulação e administração urbana (SILVA; FONSECA, 2007).

1 Processo denunciado nos anos 60, por um grupo de ativistas políticos, artistas e intelectuais, como Guy Debord, que criticavam um certo tipo de planejamento urbano, definido previamente sem a participação ativa dos cidadãos. Planejamento este, que estático, levava as cidades a se tornarem verdadeiros espetáculos para turistas, reduzindo com isso, sua apropriação por parte dos moradores (JACQUES, 2003). 
Entendemos que maiores possibilidades de apropriação corporal da cidade podem gerar não só novas formas de uso da mesma, por parte da população, mas reverterem-se também, em novas reflexões e intervenções políticas do poder público, mais próximas aos interesses dos cidadãos.

A cidade, portanto, não só deixa de ser cenário quando é praticada mas, mais do que isso, ela ganha corpo, e tornando-se "outro" corpo. Dessa relação entre o corpo do cidadão e esse "outro corpo urbano" pode surgir uma outra forma de apreensão urbana, e, consequentemente, de reflexão e de intervenção na cidade contemporânea (BRITO; JACQUES, 2008, p. 81).

Por isso, é importante questionarmos as apropriações corporais efetivadas no cotidiano lúdico das nossas cidades, de forma a identificarmos caminhos alternativos traçados pelos corpos dos cidadãos, que resistindo ${ }^{2}$ tanto ao processo de espetacularização, quanto à homogeneização esportiva dos tempos e espaços urbanos - segundo ponto da nossa problemática - possam ser considerados pelos gestores públicos, enquanto elementos necessários à formulação e consolidação de políticas participativas de lazer.

Em Bodocongó, bairro da cidade de Campina Grande, situado no interior da Paraíba, a apropriação do espaço urbano, nas experiências lúdicas dos seus moradores, se dá em meio a condições ambientais muitas vezes adversas, revelando a necessidade de políticas públicas que realmente efetivem o direito ao lazer e não apenas ofereçam estratégias de sobrevivência à população ${ }^{3}$.

2 No sentido conferido por Certeau (1998), quando discute a ideia de "tática", enquanto prática antidisciplinar que subverte as estratégias de poder, responsáveis pelo controle e organização do espaço social.

3 Novamente nos inspiramos nas ideias de Certeau (1998), para quem a noção de "estratégia" remete ao conjunto de operações utilizadas para organizar e controlar o espaço social. Quando falamos em "estratégias de sobrevivência", relacionadas às políticas públicas de esporte recreativo e de lazer, estamos nos referindo a intervenções do tipo "pão e circo", recorrentes nas administrações públicas brasileiras, que ao invés de políticas sociais concretas, agem maquiando os problemas existentes. 


\section{Bodocongó: a vida ao redor do açude}

O bairro de Bodocongó tem como principal referência o açude do qual recebe o nome, construído em 1917 por conta da escassez de água, na região, uma vez que outros açudes da cidade já não estavam suprindo as necessidades da população. Imortalizado na letra da música de Humberto Teixeira e Cícero Nunes e popularizado pelas vozes de Helena de Lima e Elba Ramalho, o açude de Bodocongó vive hoje uma dura realidade, já que se encontra bastante poluído, em virtude do lançamento de esgoto doméstico, industrial e hospitalar em suas águas, além da utilização agressiva da própria população ${ }^{4}$.

Ao seu redor, o bairro continua crescendo, muitas vezes de forma desordenada. Segundo dados do Instituto Brasileiro de Geografia e Estatística - IBGE (2002), Bodocongó é um dos maiores bairros periféricos de Campina Grande, tendo uma população que ultrapassa atualmente a quantidade de 13 mil habitantes.

O crescimento desordenado do bairro faz com que os seus limites territoriais sejam confusos até mesmo para a população que o habita, visto que através de nossa pesquisa de campo, pudemos identificar visões distintas sobre sua área geográfica.

A presidente da Sociedade Amigos do Bairro - SAB Bodocongó, por exemplo, não reconhece a "Vila dos Teimosos" ${ }^{5}$, como sendo parte do bairro. Diferentemente de moradores dessa comunidade que, quando questionados sobre a que bairro pertenciam, não hesitaram em apontar o bairro de Bodocongó.

Se levarmos em conta a lei municipal de divisão de bairros $\mathrm{n}^{\mathrm{o}}$. 1.542/87, a "Vila dos Teimosos" se encontra nos limites do bairro de

4 Apesar de ser objeto de preocupação e investimentos tanto do poder público quanto da sociedade civil organizada, o açude de Bodocongó encontra-se hoje em uma situação delicada. Segundo recente pesquisa, as águas do açude de Bodocongó não atendem aos padrões da Resolução 357/05 do Conselho Nacional do Meio Ambiente - CONAMA, revelando-se impróprias para usos múltiplos, como irrigação e lazer. Segundo os autores do estudo, as principais fontes de poluição de suas águas são: lançamento de esgoto, águas de lavagem de carros, matadouro clandestino e disposição inadequada de resíduos sólidos (CARVALHO; MORAES NETO; LIMA, et al, 2008).

5 Comunidade ribeirinha que recebeu este nome justamente por ignorar as possibilidades de aumento do nível das águas do açude Bodocongó, preferindo permanecer no local mesmo com o risco de inundações. 
Bodocongó, com os bairros Novo Bodocongó e Universitário, sendo que, por estarem situadas às margens do açude, boa parte de suas moradias encontram-se dentro dos limites territoriais de Bodocongó.

Prova de que um mapa urbano, mesmo que oficial, não pode ser tomado como única referência na determinação de uma comunidade, já que não corresponde, de forma absoluta, às diversas dinâmicas territoriais e sociais presentes no local que representa. Em Bodocongó, bairro constituído através da incorporação de conjuntos e invasões, a questão territorial se apresenta como um dos primeiros desafios na elaboração de políticas sociais que atendam aos interesses de sua população.

Isso porque os canais institucionais que a representam, como a SAB Bodocongó, muitas vezes, utilizam critérios territoriais para essa função, de forma que qualquer entendimento diferente sobre onde começa e termina o bairro, pode fazer com que parte dos seus moradores fiquem desassistidos, ou, na melhor das hipóteses, tenham outra representação.

No caso da "Vila dos Teimosos", por exemplo, o não reconhecimento da presidente da SAB local, em relação ao seu pertencimento ao bairro de Bodocongó, faz com que os moradores daquela comunidade não possam reivindicar melhorias para sua área, a partir deste canal institucional, já que só participam das suas reuniões, os moradores que, na visão dos gestores, fazem parte do bairro.

No nosso entendimento, qualquer ideia de divisão dentro do bairro, seja ela territorial ou social, não favorece em nenhum momento a implantação de políticas públicas de esporte recreativo e de lazer para a comunidade, já que diminui as possibilidades de participação e organização popular, além de aumentar os conflitos internos, reduzindo a força de reivindicação da população.

Considerando a falta de saneamento básico e as péssimas condições de moradia dessa comunidade, essa situação só torna ainda mais difícil a vida às margens do açude Bodocongó. Sem um sistema de esgotamento sanitário adequado e ruas calçadas para um melhor acesso do sistema de coleta de lixo, entre outros problemas estruturais semelhantes, soa utópico para muitos do próprio local, a reivindicação de 
políticas públicas de esporte recreativo e lazer para os moradores da "Vila dos Teimosos".

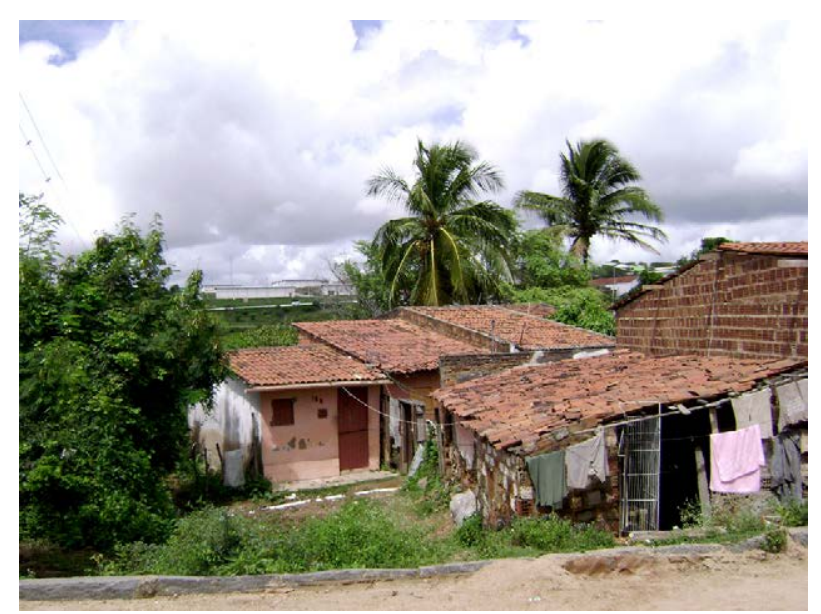

Imagem 01: "Vila dos Teimosos": sobrevivência às margens do açude de Bodocongó

Fonte: Arquivos do GCEM

Apesar disso, a comunidade vem sendo atendida, juntamente aos demais moradores do bairro, por políticas sociais de esporte e lazer, como a da Universidade Estadual da Paraíba - UEPB. Através de programas e projetos que atendem principalmente crianças e idosos da região, de forma gratuita, a UEPB vem suprindo algumas carências no tocante ao esporte recreativo e ao lazer.

Somente um de seus projetos, atende cerca de 340 pessoas de toda a cidade, sendo que em razão da UEPB estar localizada em Bodocongó, o número de moradores desse bairro corresponde a aproximadamente um terço dos participantes, o que significa uma boa frequência dos moradores de Bodocongó em relação à população dos demais bairros, mas ainda assim, é insuficiente frente a quantidade de moradores dessa área.

A Universidade Federal de Campina Grande - UFCG, outra instituição educacional situada próxima a Bodocongó, também já chegou 
a oferecer ações de esporte e lazer para a comunidade, o que favorecia os moradores do bairro. Atualmente, porém, ela não dispõe de nenhum projeto ou programa do tipo, abertos à comunidade em geral, pois tudo é voltado para a comunidade acadêmica.

Alega-se, por parte da administração do setor, existirem poucos equipamentos e muitos discentes na instituição, o que inviabiliza a divisão do espaço. Compreendemos que pela sua localização privilegiada e sua função social junto à sociedade brasileira, as universidades públicas citadas, constituem-se em ótimas possibilidades para que a população de Bodocongó possa ter efetivado o seu direito ao lazer.

É preciso, porém, que essas instituições tornem-se mais acessíveis à comunidade em geral, não se fechando em um academicismo perverso, que vê o mundo fora das universidades apenas como laboratório de pesquisas ou campo de estágios para seus professores e alunos.

Uma outra ação que atinge os moradores do bairro, é o Programa de Erradicação do Trabalho Infantil - PETI, desenvolvido pela Secretaria Municipal de Ação Social - SEMAS. O PETI atende crianças e adolescentes com idade escolar entre 7 a 15 anos, oferecendo a prática de atividades esportivas em horário contrário ao das aulas. Assim como no projeto existente na UEPB, estar matriculado e frequentar a escola são critérios utilizados para a entrada e permanência dos alunos no programa.

O lazer, tido como direito social, é entendido por nós como meio para o alcance da cidadania. Mas, para que possamos ter efetivamente o lazer como direito constituído, são necessárias políticas públicas que, além da gratuidade e qualidade, não estabeleçam tantas barreiras para a participação da população, tornando-se mais acessíveis.

Entendemos que a criação de critérios positivos para essa participação, como a otimização da vivência escolar, são ações intersetoriais necessárias à educação da população. Queremos alertar, porém, para a necessidade de pensarmos em políticas públicas de esporte recreativo e lazer que estejam ao alcance daqueles que não se encontram no processo de escolarização, já que estes são fenômenos, também, importantes para a educação da população. 
Programas gratuitos, como o "Campina Bem-Estar”, da Prefeitura Municipal de Campina Grande, que funcionava no bairro, realizando um trabalho de aferição da pressão arterial, peso e altura, das pessoas que caminhavam próximo ao açude. Programa este, que foi suspenso há pouco tempo, já que segundo uma de nossas entrevistadas, pessoas da própria comunidade danificaram o ponto de apoio que servia para a sua realização.

De acordo com Suassuna, Almeida, Freire e Roquete (2007), para que o desenvolvimento de ações sociais nos municípios ocorra, fazse necessário estabelecer políticas públicas não só de governo, mas principalmente de Estado, que não venham a acabar nas mudanças de gestão. Consideramos, ainda, que a participação popular é de extrema importância para que isso ocorra, seja colaborando com a elaboração e efetivação de novas propostas, ou pelo menos respeitando o patrimônio público.

No caso da participação da SAB e de outros grupos da sociedade organizada de Bodocongó, é importante o reconhecimento das ações que se desenvolvem no bairro, para que se possa orientar a população e exigir políticas públicas de qualidade, que possibilitem a transformação social e não estejam dentro da lógica do "pão e circo", enquanto estratégias de controle da população.

Situação que no caso de Bodocongó se mostrou mais complicada, como veremos a seguir, já que os gestores entrevistados não reconheceram nenhuma das ações e espaços públicos citados anteriormente, enquanto possibilidades de experiências de lazer dos moradores do bairro.

\section{Participação e organização popular em Bodocongó}

O movimento comunitário começa a surgir de forma mais organizada em Campina Grande, no ano de 1958, quando uma espécie de Conselho Comunitário é criado, tendo como objetivo conscientizar a comunidade dos seus problemas cotidianos. A partir daí, as Sociedades de Amigos de Bairro - SABs, são criadas e se proliferam, inspiradas 
na experiência organizacional de estados como São Paulo, onde a participação política comunitária vinha tendo sucesso (SOUSA, 2006).

Tendo como objetivo reivindicar do poder público melhorias em seus bairros, as SABs de Campina Grande passam a ser coordenadas em 1964, em pleno regime militar, pela União Campinense de Equipes Sociais - UCES, órgão que ainda hoje coordena, orienta e fiscaliza as atividades das entidades a ele associadas, no intuito de facilitar a reivindicação popular na cidade.

Dentro desta visão, a união das SABs constituiu-se num instrumento poderoso de reivindicação popular, exigindo uma equidade social para todos os subúrbios, desde o Bairro das Nações até a recém-nascida Vila dos Teimosos em Bodocongó (SOUSA, 2006).

Em Bodocongó, uma das principais instituições representantes da comunidade, junto à esfera pública, é a SAB local. Fundada há mais de trinta anos, possui atualmente cerca de 600 sócios, participantes da entidade.

Segundo seu estatuto geral (UCES, 2009), as SABs não devem ter preconceito de raça, cor, opção sexual, credos religiosos, nem tampouco, favorecer partidarismos políticos. Acontece, porém, que seguindo a tradição histórica de sua constituição no país, onde muitas vezes eram transformadas em currais eleitorais de políticos populistas, as SABs de Campina Grande ainda deixam as questões político-partidárias se sobreporem aos interesses comunitários.

Vê-se, em todos os recantos do município, um atrelamento dos movimentos comunitários com as autoridades municipais, através de empreguismo ou qualquer tipo de dependência, tirando a característica principal de um movimento independente (SOUSA, 2006).

No bairro de Bodocongó, as questões político-partidárias fizeram com que o campeonato de futebol promovido pela sua $\mathrm{SAB}$, fosse levado para outro local. Esse campeonato era um dos mais bem sucedidos projetos de esporte e lazer desenvolvidos para a comunidade, que 
com a sua retirada, ficou sem nenhum evento do tipo, cuja participação masculina era muito forte.

Segundo Sousa (2006), as questões políticas fazem com que muitas vezes o desejo de ser membro de uma SAB, seja fruto de uma maior facilidade em conseguir um emprego para si ou para os seus familiares. Ainda de acordo com o autor, o trabalho de gestão das SABs deveria ser remunerado, para diminuir a vinculação e, consequentemente, a dependência política dessas instituições junto aos órgãos públicos.

E não são só os gestores das SABs que frequentemente desconsideram a independência política do trabalho comunitário. Questionada sobre a parceria com o Clube de Mães, situado ao lado da SAB Bodocongó, sua vice-presidente revela como as questões político-partidárias podem atrapalhar, ou não, o funcionamento dessas entidades.

Bem é só vizinho, mas quando elas vêm pedir alguma coisa que a gente pode servir, a gente contribui da mesma forma. Agora, o pessoal assim... o pessoal geralmente tem um entendimento político diferenciado, coisa que a gente não faz. A gente não faz diferença política. Mas sempre a presidente de lá tinha uma rixa política, mas a gente nunca teve não, porque a gente tá aqui para servir (Vice-presidente da $S A B$ Bodocongó).

Outro fator que pode comprometer o bom funcionamento dessas instituições, é a falta de envolvimento da população. Segundo Sousa (2006), as assembleias das SABs só conseguem reunir muita gente, quando o debatedor é uma "estrela". De acordo com o autor, a participação da comunidade nas SABs é muitas vezes comprometida, pelo pensamento de que ela é uma prestadora de serviços gratuitos da comunidade, de responsabilidade única de sua direção. Entendemos que somente com a participação de todos, é que há força para reivindicação junto aos governos.

A população deve se conscientizar de que o trabalho da SAB é um trabalho que deve ser executado por todos e não especificamente pelos seus Diretores, pois todos juntos constituem-se os organizadores do movimento. A SAB é intermediária entre as rei- 
vindicações comunitárias e os órgãos públicos e não se devem assumir determinadas tarefas que a comunidade não delegou poderes para poder resolvê-las (SOUSA, 2006).

Enquanto instituições mediadoras entre a população e o poder público, as SABs devem defender os interesses de suas comunidades. Em Campina Grande, um espaço onde isso pode ocorrer de forma mais efetiva, são as reuniões do Orçamento Participativo, que segundo Pinto (2008), constitui-se numa estratégia fundamental para as políticas sociais, já que reflete as reais prioridades dos municípios.

Através do Orçamento Participativo, por exemplo, as principais reivindicações dos moradores de Bodocongó, com relação ao esporte recreativo e ao lazer, chegaram às mãos da administração pública, via requerimentos intermediados pela $\mathrm{SAB}$ do bairro. Dentre as reivindicações mais recorrentes, podemos encontrar uma pista de caminhada e um campinho de areia, além de aulas de dança de salão.

É bem verdade que a participação popular e as reivindicações via Orçamento Participativo não são garantias de que as demandas da população venham a ser atendidas. A gestora da SAB local, alega já ter procurado o setor público para fazer algumas reivindicações, mas que nada foi atendido. É preciso então, que acompanhando a organização popular, haja mais "vontade política" para que as questões do esporte recreativo e do lazer sejam atendidas.

Na Escola Municipal de Ensino Fundamental Padre Antonino, outra instituição visitada por nós, que existe desde 1989 e possui, hoje em dia, um número de 518 alunos, as intervenções do poder público também são limitadas. Assim como ocorre com a SAB local, suas parcerias são feitas em grande parte com moradores do bairro, que voluntariamente ajudam em suas atividades ou fazem doações. Em relação ao esporte recreativo e ao lazer, existe um professor voluntário, na escola, que ministra aulas de capoeira para os alunos.

É interessante notarmos que suas reivindicações são de certa forma atendidas pela administração pública, menos no caso da quadra da escola, que segundo sua diretora, encontra-se abandonada pelo poder público. 
Nós só temos aí um esqueleto de quadra. É uma quadra de areia, mas de tanto... Há tanto tempo que tá aí e não foi mais preenchida que tá cheia de buracos. Eu já pedi pra secretaria vim preencher, mas até agora nada (Diretora da Escola Padre Antonino).

A ausência ou mesmo as limitações do poder público em atender as demandas lúdicas da população do bairro, fazem com que os seus moradores procurem outras alternativas para a vivência do esporte recreativo e do lazer. Vivências estas, nem sempre realizadas em locais adequados, do ponto de vista da integridade e da dignidade do ser humano, mas certamente vividas com muito prazer e alegria.

\section{"Felizes em Bodocongó": a cultura lúdica e a apropriação do espaço urbano}

A experiência lúdica vivida em Bodocongó, cantada nos versos da música que mencionamos anteriormente sobre o açude, mostra-nos que a vivência do esporte recreativo e do lazer, não depende da quantidade ou mesmo da qualidade de espaços e equipamentos específicos, construídos para este fim.

Eu fui feliz lá no bodocongó

Com meu barquinho de um remo só

Quando era lua

Com meu bem

Remava à toa

Ai ai ai que coisa boa

Lá no meu Bodocongó

(BODOCONGó - Humberto Teixeira e Cícero Nunes)

Não queremos com isso, desautorizar ou defender um espontaneísmo na formulação de políticas sociais de esporte recreativo e de lazer, que envolvem a infraestrutura do local. Estamos apenas alertando que, nem sempre a construção de certos equipamentos específicos, 
como quadras e ginásios esportivos, resolve os problemas da população neste setor, funcionando, em muitos casos, mais como propaganda de governo.

Até mesmo porque, a cidade é apropriada pelos seus moradores de formas distintas ao que foi planejada, tornando-se o que Certeau (1998) chamaria de "lugar praticado", organizado pelas "táticas" cotidianas, ou seja, o espaço criado por movimentos que fogem ao controle total das estratégias de poder ${ }^{6}$.

Um exemplo mais prosaico, mas que talvez facilite $o$ entendimento da dinâmica descrita por Certeau, é a relação de um morador com sua moradia. Esta, planejada em algum escritório de arquitetura, prevê um ambiente, conforme as intenções do arquiteto, com uma sala, dois quartos, uma cozinha e um banheiro. Contudo, o habitar do morador é um fator de ambigüidade. Ali onde se previu uma sala eventualmente se organiza um outro aposento; o quarto talvez se transforme em um espaço para práticas religiosas, um escritório, uma "sala da bagunça das crianças", dentre outras tantas formas possíveis de habitar o lugar. De fato, esses novos sentidos dependem da construção que precede o habitar do domicílio. Contudo, o sentido dado pelo morador não é apenas estruturado pelo projeto arquitetônico, mas também estruturante daquele espaço (JOSGRILBERG, 2005, p. 24).

Em Bodocongó, a população subverte os usos oficiais da cidade fenômeno que sempre irá ocorrer, por mais que se planejem e implementem políticas sociais de lazer - de modo que defendemos, antes de qualquer coisa, uma intervenção urbana que deixe a cidade mais limpa e segura, de forma a dar condições dos seus moradores a vivenciarem sem maiores riscos.

6 Mesmo que, concordando com alguns dos seus críticos, tenhamos que entender que essas táticas, muitas vezes, venham a utilizar o sistema, sem necessariamente confrontá-lo. 


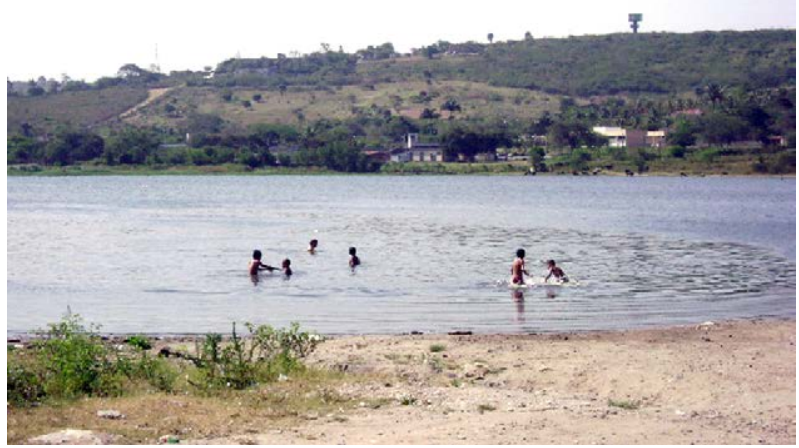

Imagem 02: Açude de Bodocongó: o lúdico convivendo com a tristeza da poluição

Fonte: Arquivos do GCEM

No açude, já não vemos tantos barquinhos compondo a paisagem urbana, mas a alegria da experiência lúdica permanece no local, mesmo em meio à poluição de suas águas, podendo ser vista nos rostos das crianças que brincam por lá, dividindo o espaço com a lavagem de carros e de animais, entre outras práticas dos moradores, que tiram o seu sustento do açude.

Outro local do bairro, onde as crianças gostam de brincar, é o canal que corta a cidade, transportando lixo e água das chuvas. Mesmo nestes locais mais inóspitos, encontramos a alegria da experiência lúdica, coexistindo com a falta de uma estrutura urbana adequada, o que faz com que as crianças do bairro apresentem diversos problemas de saúde, como micoses e verminoses acentuadas.

Entre as inúmeras idas a campo, a fim de compreendermos melhor o cotidiano do bairro, pudemos observar uma movimentação em particular, de quatro crianças no referido canal. Três delas se encontravam na parte interna, ou seja, dentro do canal, enquanto a outra apenas as observava do lado de fora. Indagamos a esta o que estava acontecendo e ela nos respondeu que havia um cachorrinho preso dentro de um buraco na parede do canal, sendo que ele não estava conseguindo sair 
porque estava com medo de cair. Questionada se gostava de brincar no canal, ela respondeu, se afastando-se dos demais, que não, que só quem brincava ali eram eles, os meninos que estavam dentro do canal. Justificando-se, disse que era porque ali era sujo, podia-se pegar doenças.

Percebemos logo as diferenças não só de comportamento, entre aqueles que brincavam e o que apenas assistia. Trajado de farda escolar, enquanto os outros estavam "mauvestidos", ele parecia um pouco triste por não participar do "resgate", enquanto os demais se divertiam bastante com a história do cachorro, mesmo expostos a uma situação na qual poderiam contrair alguma doença. Sabemos que todas elas residiam no mesmo bairro, o que revela as diferenças existentes entre os moradores de uma mesma localidade, parte de um processo sociocultural visível em toda parte, mesmo em se tratando de um bairro periférico como Bodocongó.

Outra brincadeira comum, no bairro de Bodocongó, é a de empinar pipas, que frequentemente enrolam-se nos fios de alta tensão, trazendo riscos para as crianças que as confeccionam. Uma rápida olhada para o céu que cobre o bairro, dá-nos uma ideia da quantidade de pipas que diariamente se perdem no cotidiano lúdico das crianças de Bodocongó.

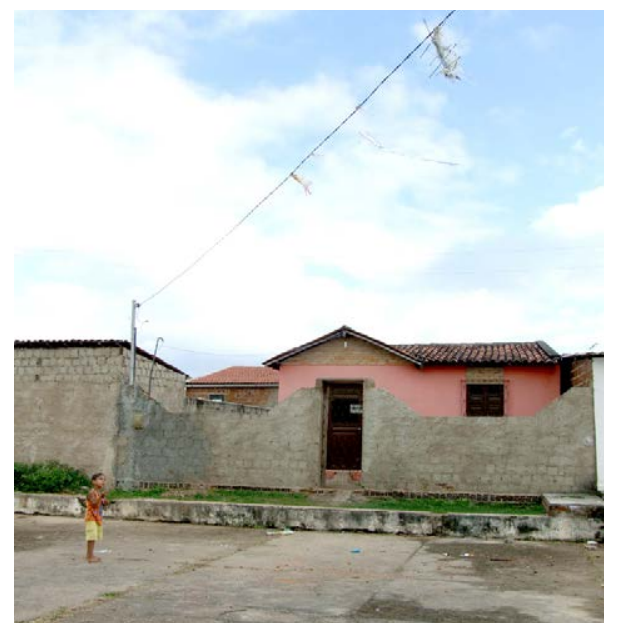

Imagem 03: Pipas: fontes de perigo e alegria em Bodocongó

Fonte: Arquivos do GCE 
Em se tratando do esporte recreativo dos moradores de Bodocongó, pudemos observar a presença constante do futebol, que ora disputando espaço com os carros, nas ruas movimentadas do bairro, ora convivendo com animais de diversos tipos e condições de saúde, insiste em se perpetuar, principalmente nos campos improvisados que ainda existem no local.

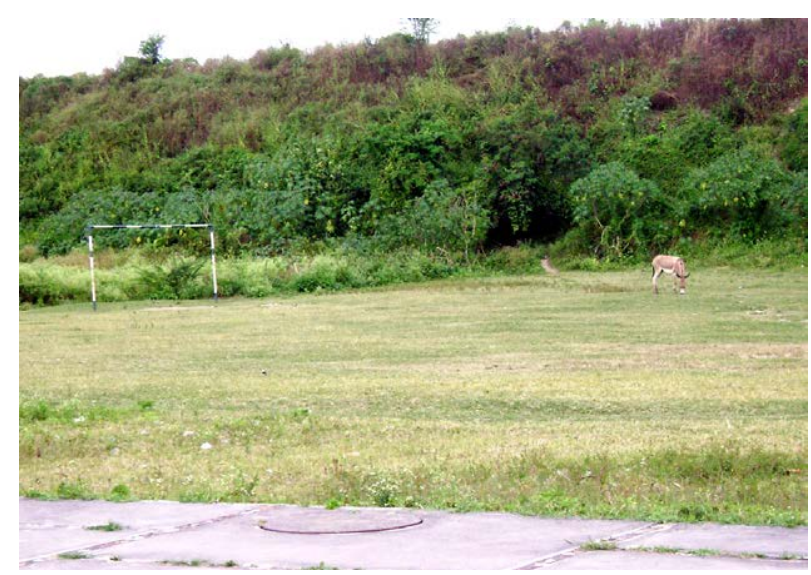

Imagem 04: Campos improvisados: opção de lazer disputada por todas as espécies

Fonte: Arquivos do GCEM

Mas não são apenas esses espaços ou manifestações que têm vez em Bodocongó. Os quadros, a seguir, mostram a riqueza de possibilidades lúdicas encontradas no bairro. Mesmo que possivelmente não retratem, de forma absoluta, a realidade existente em Bodocongó, já que sua grande extensão não nos permitiu uma varredura territorial completa, esses quadros trazem elementos significativos para pensarmos as políticas públicas de esporte recreativo e de lazer do bairro. 0 quadro 1, por exemplo, descreve os principais equipamentos e espaços de lazer identificados em Bodocongó, através dos discursos dos nossos entrevistados ou das nossas idas a campo. 


\begin{tabular}{|c|c|c|c|}
\hline Local & Tipo & Quantidade & Condições de uso \\
\hline UEPB & $\begin{array}{l}\text { Complexo esporti- } \\
\text { vo da UEPB }\end{array}$ & 1 & $\begin{array}{l}\text { Sem problemas } \\
\text { aparentes }\end{array}$ \\
\hline \multirow{3}{*}{$\begin{array}{l}\text { Açude de } \\
\text { Bodocongó }\end{array}$} & Ciclovia & 1 & $\begin{array}{l}\text { Com buracos em } \\
\text { alguns pontos }\end{array}$ \\
\hline & $\begin{array}{l}\text { Pista de cami- } \\
\text { nhada }\end{array}$ & 1 & $\begin{array}{l}\text { Com buracos em } \\
\text { alguns pontos }\end{array}$ \\
\hline & Açude & 1 & Poluído \\
\hline \multirow{5}{*}{$\begin{array}{c}\text { Bairro de } \\
\text { Bodocongó }\end{array}$} & Ruas & - & Trânsito de leve a intenso \\
\hline & Esquinas & - & $\begin{array}{l}\text { Sem problemas } \\
\text { aparentes }\end{array}$ \\
\hline & $\begin{array}{l}\text { Campos improvi- } \\
\text { sados }\end{array}$ & - & $\begin{array}{l}\text { Geralmente com mato e } \\
\text { animais presentes }\end{array}$ \\
\hline & $\begin{array}{l}\text { Antigo terreno do } \\
\text { matadouro }\end{array}$ & 1 & Não observado \\
\hline & Canal & 1 & Poluído \\
\hline $\begin{array}{c}\text { SAB } \\
\text { Bodocongó }\end{array}$ & Quadra & 1 & $\begin{array}{l}\text { Sem iluminação e com } \\
\text { problemas no piso }\end{array}$ \\
\hline \multirow{5}{*}{$\begin{array}{l}\text { Escola Padre } \\
\text { Antonino }\end{array}$} & Pátio & 1 & $\begin{array}{l}\text { Sem problemas } \\
\text { aparentes }\end{array}$ \\
\hline & Espaços livres & - & $\begin{array}{c}\text { Sem problemas } \\
\text { aparentes }\end{array}$ \\
\hline & Quadra & 1 & $\begin{array}{l}\text { Desnivelada, com } \\
\text { quinas à mostra }\end{array}$ \\
\hline & Sala de leitura & 1 & $\begin{array}{c}\text { Sem problemas } \\
\text { aparentes }\end{array}$ \\
\hline & $\begin{array}{c}\text { Espaço atrás da } \\
\text { escola }\end{array}$ & 1 & Não observado \\
\hline
\end{tabular}

Quadro 1 - Espaços e equipamentos para o esporte recreativo e o lazer, existentes no bairro de Bodocongó 
Podemos observar através deste quadro, a existência de espaços e equipamentos planejados para a prática do esporte recreativo e do lazer em Bodocongó, mesmo que em alguns casos, não estejam em boas condições de utilização. 0 maior problema desses espaços e equipamentos, porém, é que eles não se encontram, em sua maioria, disponíveis à população do bairro, já que possuem regras específicas de uso, como aqueles localizados nas escolas públicas.

É o caso da Escola Municipal de Ensino Fundamental Padre Antonino, que através da instalação de segurança eletrônica em seu prédio, fez com que a possibilidade de utilização da mesma nos finais de semana acabasse, já que não havia mais seguranças na escola, que pudessem desligar o alarme para a entrada da comunidade.

Segundo Stucchi (1997), todo equipamento de lazer deve estar situado, de alguma maneira, próximo aos setores residenciais, para que determinada população usufrua de suas instalações. Muito embora, percebemos em Bodocongó, a falta de espaços e equipamentos específicos, adequados e acessíveis para a utilização da comunidade.

De acordo com os nossos dados, a SAB local é um dos principais espaços de lazer existentes no bairro. Sem praça pública que possa ser utilizada como um espaço seguro e agradável para o convívio social, os adultos de Bodocongó costumam se deslocar para bairros vizinhos, como o Centenário, para vivenciarem o esporte recreativo e o lazer.

Segundo visto em nossa pesquisa, uma das únicas práticas de lazer existentes para a comunidade adulta atualmente, é o jogo de dominó nas esquinas, além da caminhada na pista ao lado do açude e o futebol no terreno do antigo matadouro. É importante reforçar a necessidade de que os espaços e equipamentos existentes estejam sempre em manutenção, ou seja, em bom estado de conservação, para o bom aproveitamento de quem os utiliza, pois caso isso não ocorra, eles não serão mais utilizados ou poderão trazer prejuízos à população. 


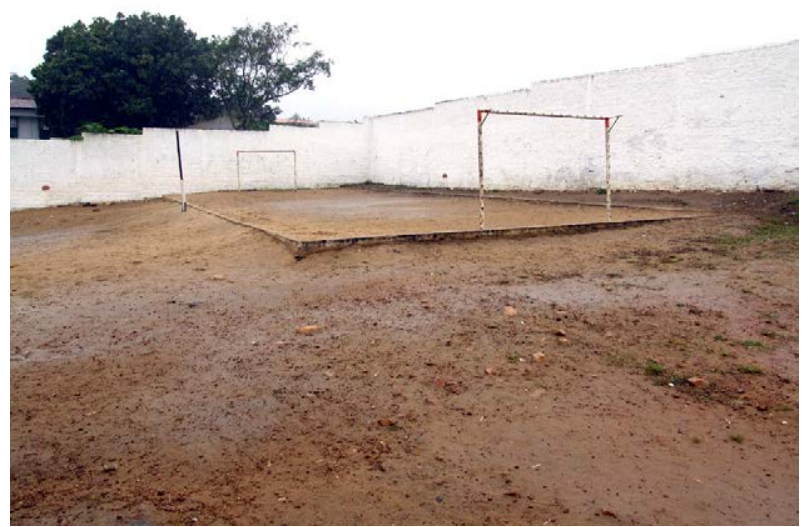

Imagem 05: Quadra da escola: regras específicas e má conservação

Fonte: Arquivos do GCEM

Os eventos, realizados no bairro, revelam uma série de manifestações culturais existentes em Bodocongó, como podemos observar no quadro a seguir, que precisam de uma maior atenção do poder público, no sentido de serem preservadas, já que muitas vezes, carregam consigo a memória e a identidade cultural do bairro. 


\begin{tabular}{|c|c|c|}
\hline $\begin{array}{c}\text { Manifestações culturais } \\
\text { e eventos }\end{array}$ & $\begin{array}{l}\text { Formas de } \\
\text { vivência }\end{array}$ & Temporalidade \\
\hline \multirow{3}{*}{ Futebol } & $\begin{array}{l}\text { Jogos recreativos dos } \\
\text { jovens }\end{array}$ & Diariamente \\
\hline & $\begin{array}{l}\text { Partidas entre os times } \\
\text { dos adultos }\end{array}$ & Finais de semana \\
\hline & Aulas & Semanalmente \\
\hline $\begin{array}{l}\text { Dia das mães, dos pais, } \\
\text { dos avós, dos estudantes } \\
\text { e da criança }\end{array}$ & Festividades & Uma vez por ano \\
\hline $\begin{array}{l}\text { Mostras culturais } \\
\text { e gincanas }\end{array}$ & Festividades & Eventualmente \\
\hline $\begin{array}{l}\text { Pega-varetas; dominó; } \\
\text { damas e xadrez }\end{array}$ & Brincadeiras & Diariamente \\
\hline $\begin{array}{l}\text { Pipa; bila; baleada; pega-pega } \\
\text { e polícia e ladrão }\end{array}$ & Brincadeiras & Diariamente \\
\hline Quadrilhas juninas & Ensaios & $\begin{array}{l}\text { Primeiro semestre do } \\
\text { ano }\end{array}$ \\
\hline \multirow{3}{*}{ Capoeira } & Aulas & Período escolar \\
\hline & Treinos & Semanalmente \\
\hline & Exercícios & Diariamente \\
\hline Bingo & Festividade & Eventualmente \\
\hline Serestas e "louvorsões" & Festividades & Eventualmente \\
\hline Festa de São João & Festividade & Uma vez por ano \\
\hline Aniversários e festas de casamento & Festividades & Eventualmente \\
\hline Bandas & Ensaios & Semanalmente \\
\hline Dança & Vivência & Semanalmente \\
\hline Atividade Física & Vivência & Diariamente \\
\hline Corrida Volta do Bodocongó & Competição & Anualmente \\
\hline $\begin{array}{l}\text { Dança, basquetebol, futsal, voleibol, } \\
\text { natação, judô, handebol, tae kwon } \\
\text { do e ginástica de academia }\end{array}$ & Aulas & Semanalmente \\
\hline
\end{tabular}

Quadro 2 - Manifestações culturais e eventos existentes no bairro de Bodocongó 
Um evento que gostaríamos de destacar no momento, pelo fato de unir educação, saúde e lazer em uma mesma iniciativa, é a corrida "Volta do Bodocongó" que, em 2009, chegou a seu terceiro ano consecutivo. Promovida pela UEPB em parceria com a SAB do bairro, este evento teve o intuito de conscientizar a população sobre a importância da preservação e revitalização do açude.

A corrida contou com o apoio da população de Bodocongó, que durante o evento, recebeu quinhentas mudas de diversas árvores, originárias da escola agrícola da UEPB. Ao final do evento, houve comemoração com festa dançante às margens do açude, animada por um conjunto musical do próprio bairro.

Assim como os espaços apropriados pela população do bairro de Bodocongó, em sua experiência lúdica do lazer, não se limitam aos equipamentos construídos para este fim, as manifestações culturais e os eventos vivenciados no bairro, na maioria das vezes, não fazem parte do calendário oficial de festividades da cidade.

Consideramos importante então, que numa perspectiva intersetorial, o poder público estabeleça políticas culturais capazes de reconhecerem em Bodocongó, eventos e manifestações que traduzem a memória e a identidade cultural de sua população, de forma que elas não desapareçam do cotidiano lúdico do bairro.

\section{Considerações finais}

De acordo com o que apresentamos ao longo deste texto, podemos notar a fragilidade dos espaços e equipamentos específicos de lazer existentes no bairro de Bodocongó, quando focalizamos especificamente suas condições de uso, o que reforça a necessidade de políticas públicas que realmente efetivem o direito ao lazer e não apenas ofereçam estratégias de sobrevivência à população.

Muito embora tenhamos escrito em lei, que todo cidadão tem direito ao lazer de forma digna, o que vemos por lá, é a apropriação corporal dos espaços urbanos, acontecendo em muitos casos, em condi- 
ções ambientais precárias. Fato este que não impede a emergência do lúdico em todos os cantos do bairro, mesmo naqueles mais humildes, como é o caso da "Vila dos Teimosos".

Até porque, como pudemos observar, a experiência lúdica não depende exclusivamente do aporte financeiro que se tem, sendo encontrada, em Bodocongó, no futebol que se joga no meio da rua ou no jogo de dominó das esquinas, entre outras manifestações culturais encontradas.

Como os espaços urbanos vêm se tornando objetos de decoração das grandes cidades, não sendo projetados para serem apropriados corporalmente, como podemos ver até mesmo em Bodocongó, através do "girador"7 que leva a população ao bairro, os moradores veem-se obrigados a se adequar a uma cidade mal planejada, e ainda, a se submeter às diversas formas de violência contidas nela.

Retomando a questão das políticas intersetoriais de lazer, especificamente na interface do lúdico com o desenvolvimento urbano, alertamos para a necessidade de um planejamento que considere o vivido da população, ou seja, que parta e termine na apropriação corporal do espaço urbano, tendo em vista as resistências efetuadas no cotidiano da população.

Planejamento este, que não se limite à construção de cidades "cenográficas" ou mesmo "esportivizadas", mas que, acima de tudo, invista na integridade de seus habitantes, para que eles possam vivenciar o espaço urbano sem maiores riscos e continuar cantando, assim como em Bodocongó, como foram felizes por lá.

\section{Referências}

BRITO, F. D.; JACQUES, P. B. Cenografias e corpografias urbanas: um diálogo sobre as relações entre corpo e cidade. CADERNOS PPG-AU/ FAUFBA, Salvador, v.7, 2008. Edição Especial.

7 Elemento organizador da malha viária, comum na cidade de Campina Grande, que cercado por trânsito intenso, apresenta-se pouco acessível à presença da população. 
CARVAlHO, A. P.; MORAES NETO, J. M.; LIMA, V. L. A.; et al. Aspectos qualitativos da água do açude de Bodocongó em Campina Grande - PB. Engenharia Ambiental, v. 5, n. 2, 2008.

CERTEAU, M. A invenção do cotidiano: artes de fazer. Petrópolis: Vozes, 1998.

CHEMIN, B. F. Políticas públicas de lazer: o papel dos municípios na sua implementação. Curitiba: Juruá, 2007.

IBGE - Instituto Brasileiro de Geografia e Estatística.Censos Demográficos 1991/2000. 2002.

JACQUES, P. B. (Org.). Apologia da deriva: escritos situacionistas sobre a cidade. Rio de Janeiro: Casa da palavra, 2003.

JOSGRILBERG, F. B. Cotidiano e invenção: os espaços de Michel de Certeau. São Paulo: Escrituras Editora, 2005.

MARCELLINO, N. C. Estudos do lazer: uma introdução. Campinas: Autores Associados, 2002.

PINTO, L. M. S. M. Estado e sociedade na construção de inovações nas políticas públicas sociais de lazer no Brasil. In: MARCELLINO, N. C. (Org.). Políticas públicas de lazer. Campinas: Alínea, 2008.

SILVA, R. H. A.; FONSECA, C. G. Cartografias urbanas: lugares, espaços e fluxos comunicativos. In: Encontro da Compós, 16, 2007, Curitiba. Anais... Curitiba, 2007.

SOARES, C. L. Cultura de movimento. In: SESC. Corpo, prazer e movimento. São Paulo: SESC-SP, 2007.

SOUSA, L. G. Economia, política e sociedade. 2006. Disponível em: <http://www.eumed.net>. Acesso em: 14 abr 2009. 
STUCCHI, S. Espaços e equipamentos de recreação e lazer. In: BRUHNS, H. T. (Org.). Introdução aos estudos do lazer. Campinas: Editora da Unicamp, 1997.

SUASSUNA, D.; ALMEIDA, A. J. M.; FREIRE, J. O.; ROQUETE; P. C. O Ministério do Esporte e a definição de políticas para o esporte e lazer. In: SUASSUNA, D.; AZEVEDO, A. A. (Orgs.). Política e lazer: interfaces e perspectivas. Brasília: Thesaurus, 2007.

UNIÃO CAMPINENSE DAS EQUIPES SOCIAIS. Estatuto. Campina Grande, 2006. Disponível em: <http://www.ucescg.com.br/estatutos. html>. Acesso em: 14 abr. 2009. 